\title{
Teaching Thinking on "activity" in Middle School Geography Textbooks
}

\section{Xiuqin Zhuang}

(School of Urban and Environment, Huaiyin Normal University, Huai' an, Jiangsu, 223001)

\begin{abstract}
Activity" in middle school geography textbooks is characteristic by diversity, openness. Inquiry can better meet the requirements for new textbooks and stimulate students' passion for geographical study. But because of limited lesson hours, it's often ignored by many teachers. Thereafter, we analyze problems and put forward solution to address them on the basis of questionnaire for teaching situation on "activity" in middle school geography classes to ensure to reach its teaching targets as expected.
\end{abstract}

Keywords: High school geography; "Activities" section; Teaching strategies

\section{初中地理教材中“活动”板块的教学思考 \\ 庄秀琴}

淮阴师范学院城市与环境学院, 江苏, 淮安, 223001

摘要: 初中地理教材中的 “活动” 板块具有多样性、开放性、探究性的特点, 能够很好的适应新课改的要求, 可以激起 学生的地理学习热情。但限于教学时数, 很多老师对这一板块的教学处理都不够重视。据此, 在对初中地理棵堂的“活动” 板块教学情况进行问卷调查的基础上，分析存在问题，提出改进措施，以确保“活动”板块的教学能达到预期效果。

关键词: 初中地理; “活动” 板块; 教学策略

中图分类号: G632.0 文献标志码: A

\section{1 引言}

建构主义学习理论强调每个学生都不是空着脑袋进教室的, 而是通过教师的引导主动重组、改造已有 的知识经验, 从而学到新知识。它强调学生间的合作学习。新一轮课程改革也强调学生要自主、探究、合 作学习, 提高知识迁移的能力, 使学生全面、长久地发展, 帮助他们主动构建认知结构, 形成清晰的知识 体系。人教版初中地理教材中 “活动” 板块的设计既符合这一学习理论, 也体现了新课程改革的要求, 注重以学生为中心、在实际情境中组织教学, 以培养学生树立主动构建意识, 用指导学生独立思考和实践 活动的方式来传递地理教学信息。但现阶段 “活动” 板块的教学仍存在诸多的问题, 学生是否积极参与活 动、主动学习; 是否分工明确、合作学习; 教师在思想上是否重视 “活动” 板块的教学; 是否考虑到学生 的个体差异性; 是否积极创新 “活动” 形式激发学生学习热情等等这些问题都需要进一步的研究探讨。

\section{2 “活动” 板块概述}

进行课程改革首先要改革教材, 无论是哪种版本的初中地理教材, 改革的最明显特征就是 “活动”板 块数量的增多和 “活动” 内容的丰富, 教材在每一节中都设置了 “活动” 板块。希望通过 “活动” 板块的 运用, 将地理知识与地理技能有机地结合起来, 并通过学生小组间的合作、探究、交流等多种学习活动, 让学生真正参与到教学活动中来, 切实体现学生的主体地位。 


\section{1 设置 “活动” 板块的目的}

以罗杰斯等为代表的人本主义学习论主张学习者是完整的人, 学校应注重培养学生的整体人格, 强调 课程内容要与学生的生活实际相联系, 使学生 “有意义” 地学习。新课改则强调 “学习对生活有用的地理”。 “活动” 板块设置了大量与学生生活息息相关的、趣味性很强的地理问题, 其目的是让学生在参与课堂活 动过程中体验学习, 在享受轻松活泼的活动中自主构建知识, 实现 “一切为了学生发展” 的新课改核心理 念 [1]。教师在教学中鼓励学生独立思考, 自由表达情感和观点, 及时对学生进行指导和总结, 营造欢快 轻松的课堂氛围, 促进学生有意义学习, 更好地发展潜能, 拓展学生的思维和实践创新的能力。

\section{2 “活动” 板块的类型}

谢婷在《人教版地理八年级上册活动栏目教学研究》中对教材 “活动” 板块的分类进行了研究, 按照 活动内容将其分为六种主要类型：读图填图类、图表分析类、资料搜集类、社会调查类、问题讨论类和设 计撰文类 [2]。地理图表类活动包括读图、填图、填表。无论是地理知识的学习还是地理问题的探究都要 通过 “读图” 来完成 [3]。教师可通过图表类活动整合相关知识指导学生进行读图训练, 锻炼他们从图中 提取信息并处理等地图基本技能。图表分析类活动以图表为载体，学生通过对各类地图、表格数据中所提 供的信息资料分析总结，得出结论 [4]。资料搜集类活动是提供课本上粗略说明的知识问题的一部分相关 信息, 并针对其拓展性问题让学生凭借生活中的各种渠道如网络、书籍、报刊、电视、广播等来搜集相关 主题的资料, 从而获取感性认识, 得出自己的见解。旨在提高学生收集、篮选、分析信息, 解决问题的能 力, 有利于提高学生其他相关学科的学习, 激发学生学习兴趣。社会调查类活动则需要学生事先制定调查 步骤, 利用课余时间进行社会调查访问, 并对所获信息加以整理和归纳, 从而按计划地针对问题提出建议、 解决有关地理问题。问题讨论类板块则需要学生之间的合作学习。《课程标准》指出, “讨论是活动中最常 用的交流、学习形式 [5]。” 设计撰写类活动则是通过提出某一地理方面的热点话题, 让学生课后查阅资料 撰写相关的地理小短文或者设计主题板报等, 这种活动方式使学生的语言写作能力得到了有效的锻炼。

\section{3 “活动” 板块的特点}

“活动” 板块的特点可以总结训三个方面, 即: 类型的多样性, “活动”板块类型包括读图绘图、计 算填表、选择连线、资料搜集、讨论分析、演示实验等多种形式，使学生在学习每节内容时都能产生新颖 感和好奇感, 激发了他们对地理的学习热情; 内容的开放性, “活动” 板块设计时注重选取联系学生生活 实际和社会上的热点问题, 创设问题情境为学生进行探究提供信息作为参考, 体现新课改中强调的培养学 生搜集和处理信息的能力。但问题往往没有具体现成的答案, 开放性比较大, 给学生足够的思考空间; 过 程的探究性, “活动” 板块给学生提供内容上的一系列活动步骤以及活动指导, 引导学生在课堂上独立思 考, 自主学习, 动手操作, 并与小组间讨论交流, 让学生结合地理知识与地理技能, 在探究学习中感受自 主解决地理问题的过程, 从而达到帮助学生学会自主学习, 丰富学生的认识和情感体验, 不断自我完善和 提升的目的。

\section{3 “活动” 板块教学中存在问题}

为准确了解初中部 “活动”板块教学内容的被执行情况，对南京市某中学八年级 8 个班学生进行了问 卷调查, 一共发放 311 份, 回收 304 份, 回收率达 $97.75 \%$ 。通过对问卷的分析归纳, 发现初中地理 “活动” 板块的教学主要存在以下几个方面的问题: 


\section{1 固守传统教学模式, 缺乏主动学习意识}

在初中地理 “活动”板块的教学中，虽然教师大多都会高频率地使用各种地图、图表，或者在黑板上 绘制简易地图来辅助课堂教学, 但大多数老师仍固守传统的教学模式, 以讲授为主, 而学生又习惯性地被 动 “听讲”, 机械式地记忆并抄写课堂笔记, 接受式地学习新知识与新技能, 违背了学生在教育教学中处 于主体地位，是学习的主体 [6] 的要求。各类活动都是依赖教师的提示，忽略了自身的主观能动性，久而 久之, 学生参与活动时的新鲜感和好奇感逐渐消磨殆尽, 渐渐对地理学习失去本应有的兴趣, 学习积极性 降低, 容易走神, 影响课堂教学质量 (见图 3-1)。被动参与与几乎不参与的学生占到了总人数的 $41 \%$, 这 类学生在学习上所表现的被动性不单单只是针对地理这门学科, 而更多的是个人学习态度上的被动性。

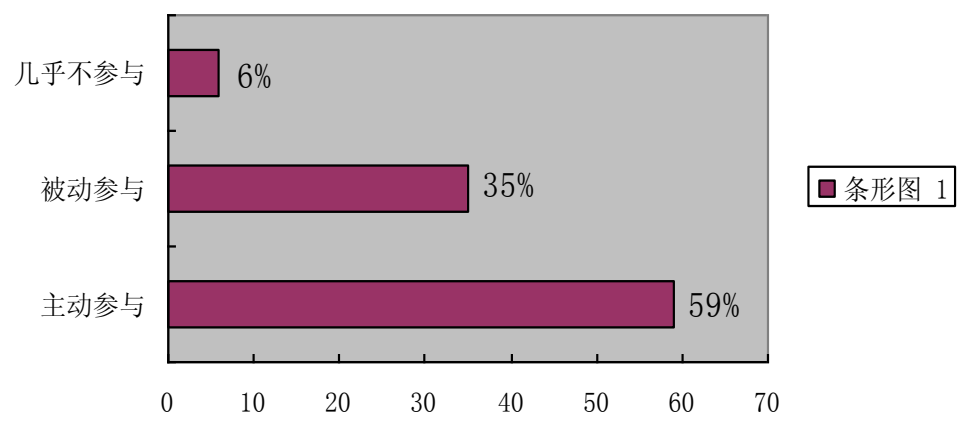

图 3-1 学生在 “活动” 板块教学开展过程中的参与情况

\section{2 师生关系协调欠佳, 缺乏团队合作能力}

初中生在小组活动中缺乏合作意识这一现象也较普遍，未能发挥合作在分析和解决问题上所起到的良 好的催化、辅助作用, 这与教师在课堂上没有组织好活动安排、协调好学生分工等有很大关系。在小组讨 论中要么大家各抒己见、相互争论; 要么互相推辞导致任务停滞 (见图 3-2)。共计有 38\%的学生处于要么 不动脑思考, 只听其他人讨论人云亦云; 要么坚持个人观点, 不耐心倾听他人不同的观点; 或者上课开小 差, 不参与讨论, 这与教师在课堂上没有扮演好引导者的角色, 没有组织协调好学生之间的合作分工有很 大关系。

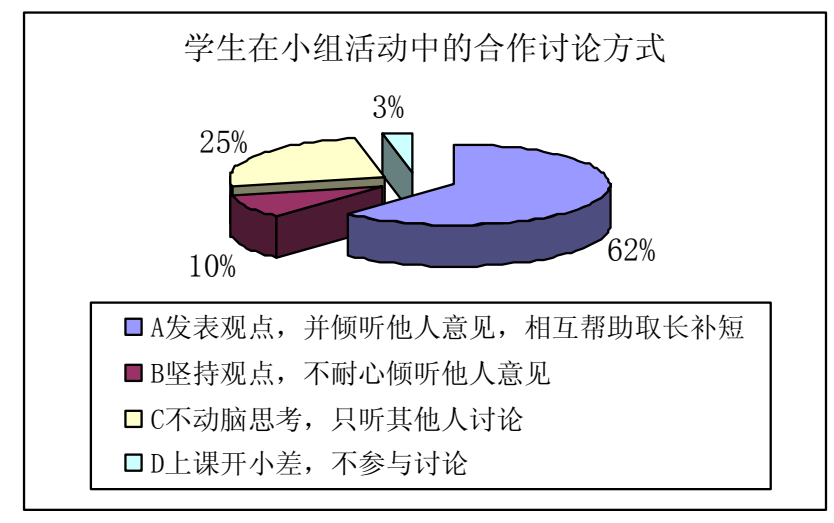

图 3-2 学生在小组活动中的合作讨论方式

\section{3 教学思想上不重视, 教材处理没有做好}

在中学初中地理属于副科，课时安排相对较少，还会被主课老师或校内活动占用上课时间，考虑到教 
学进度等问题, 大多数教师往往会缩短活动时间或简略活动方式, 有的甚至在课堂上舍弃 “活动” 板块环 节, 把活动任务交给学生课后完成。在课堂上更多的是快速讲授重要知识点, 很少花精力去改善 “活动” 设计并合理开展 (见图 3-3)。在课堂教学的实施过程中教师仍以传统的 “教师讲、学生记” 的讲授式和回 答问题式为主, 教学手段枯燥单一。另外教师在课堂上有时过于放大学生的主体性, 完全放手让学生完成, 在调查中教师把活动交给学生自主合作完成占比为。而在课堂上教师真正做到通过引导学生合作讨论、思 考问题, 并及时归纳总结得出结论的方式仅占 $40 \%$, 无法体现 “活动” 板块设置的过程探究性特点, 很难 达到 “活动” 锻炼学生分析问题、解决问题的能力，降低了教学有效性。

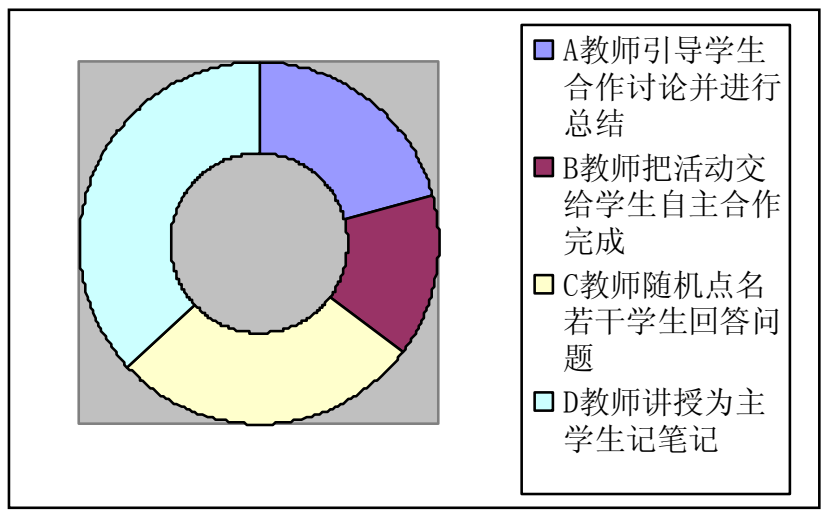

图 3-3 教师在课堂上进行活动时的教学方式

\section{4 忽视学生个体差异, 活动参与质量不一}

教育学相关理论中强调学生之间存在着性别和年龄上的个体差异, 部分学生学习习惯较好, 学习能力 较强, 在 “活动” 板块的开展过程中能积极动手动脑, 勤于思考, 探究问题。而有些学生思维不够活跃, 观察分析能力较弱, 无法很好地跟上教师教学环节的步伐, 导致教师在教学进度和教学要求上不能满足所 有学生, 影响教学质量 (见图 3-4)。有 9\%的学生基础较差, 很难独立思考解决问题; 33\%的学生在参与 “活 动”过程中有点吃力, 思维有点跟不上; 考独立完成的学生只占 $12 \%$, 因材施教就显得尤为重要。

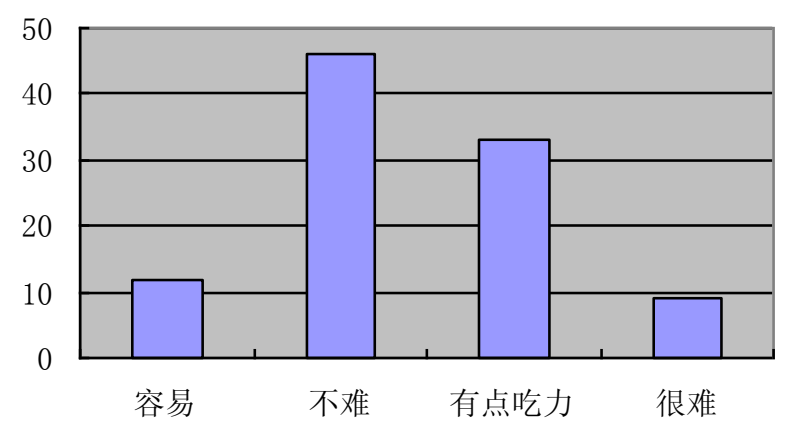

图 3-4 学生在 “活动” 中参与能力统计

\section{4 优化 “活动” 板块教学的建议}

\section{1 创设趣味情境, 吸引学生主动参与}

人教版初中地理 “活动”板块的设置本身就通过其新颖的授课方式, 活跃的课堂气氛, 调动了学生学 习的积极性, 使学生有浓厚的兴趣投入到思考实践当中。初一到初三的学生, 他们更容易被富有情感色彩 
的内容 [7]。教师要想达到满意的教学效果, 就得激发学生的地理兴趣, 这就要靠教师在现有的 “活动” 板块基础上, 经过一定的改良优化, 创设出新的趣味性的活动情境, 灵活变通, 使活动过程生动有趣, 增 强 “活动” 的趣味性。学生只有觉得学习有趣, 才会对科学知识产生了解、征服的欲望, 促使他们主动学 习, 主动思考 $[8]$, 主动地投身到教师组织的课堂活动。

\section{2 引导学生合作, 转变师生关系}

教师对学生的指导作用在活动教学中所处的地位是尤为重要的, 关乎学生的各方面能力的培养, 能够 促进学生有意义的学习。教师对于学生的学习要扮演好引导者、组织者的角色, 体现教师的主导作用。另 外, 还应注意调节学生之间的合作关系。在活动前教师要把握每个问题探讨的深度, 结合初中生的年龄特 征和知识能力水平, 向学生表明活动要求, 布置具体任务, 在活动后要适时做好分析和总结工作, 正确的 观点要表扬, 错误的要及时纠正跟补充, 使指导贯穿活动的始终。有效的语言交流可使课堂焕发生命力、 更加高效进行 [9]。因此教师要注重优化师生关系, 把教学当做是与学生合作、沟通的过程, 为学生营造 和睦轻松的氛围。

\section{3 重视活动教学, 改良课本中活动教学设计}

要想把大量的“活动”板块内容在实际的教学中较为完整地呈现，需要教师对原有“活动”板块内容 进行再加工、再设计, 使其即达到教学要求又在规定的课时安排之内完成。这就首先要求教师要认识到 “活 动” 板块在教学实施中的重要性, 对新课改的教学理念和活动教学观念进行深入剖析, 改良活动设计, 使 之更重视培养学生的动手实践和创新能力 [10]。学生在探究问题的过程中能充分运用眼、手、脑, 通过 “活 动” 培养动手、动脑能力, 从而获得生动的感知和体验, 使所学知识得到更深层次的理解。

\section{4 实施分层教学, 关注每个学生的个体差异}

人本主义学习理论强调学习者是完整的人, 而每个学生个体又都是鲜明独立的, 他们的学习习惯、学 习能力、生活环境、性格特征等方面都存在差异, 教师需要对各班级学生的学情进行分析, 了解不同层次 学生对 “活动” 过程的参与难易程度, 从学习要求、任务问题、活动作业等方面分层教学, 分层关注学生 的差异。“活动” 的设计更贴近学生的实际生活, 让学生产生亲切感, 降低学习难度。知识来源于生活, 新课改指出, 教育教学要贴近学生生活 [11]。教师可巧用问题讨论类、社会调查类等类型中的体现生活元 素的 “活动” 板块组织教学, 如人口问题、水资源保护等, 在教学活动中引导学生联系生活思考地理问题, 培养他们良好的情感态度与价值观。

\section{参考文献}

[1］孙文玲．地理教材 “活动板块” 的灵活妙用 $[J]$ ．新课程研究，2015(10)：31.

[2] 谢婷. 人教版地理八年级上册活动栏目教学研究 [D]．陕西师范大学，2013：27-28.

[3] 汪学芳. 谈地理考试中如何运用地图提高成绩 [J]。 中学地理教学参考, 2015(10)：61-62.

[4] 邓秋萍. 初中地理活动栏目教学探讨 $[\mathrm{J}]$. 上海教育科研, 2012(3)：93-94.

[5] 方明中. 实施开放式教学, 让学生动起来 $[J]$. 教育观察, 2012(1)：98-100.

[6] 丁文利. 初中地理高效课堂的构建路径探析 [J]. 新课程研究, 2014：132.

[7] 刘斌. 人教版初中地理图册修订后的特色 [J]. 中学地理教学参考, 2015(11)：42-44.

[8] 李华成. 学习地理要让学生动起来 $[J]$. 现代教育, 2011 (5)：49.

[9］于培英. 走进新课改让学生 “动起来” [J]。黑龙江教育学院学报, 2015 (1)：159-160.

[10］李文. 义务教育地理课程标准修订的五个新突破及教学思考 [J]。地理教学，2012(13)：9-11. 
[11] 周敏琴. 探究初中地理生活化教学[J]. 基础教育, 2015(23)：66.

\section{References:}

[1] Sun Wenling. Flexible Application of "Active Plate" in Geography Textbooks [J].New Curriculum Research, 2015(10):31.

[2] Xie Ting. Teaching and Research on Activities Section in Geography Eighth Grade (The First Volume, People's Education Press) [D].Shaanxi Normal University,2013:27-28.

[3] Wang Xuefang. About How to Use Map in Geography Exam to Improve Score [J].Teaching Reference of Middle School Geography, 2015(10):61-62.

[4] Deng Qiuping. Discussion on Teaching of Middle School Geography Activity Program [J]. Shanghai Academy of Educational Sciences, 2012(3):93-94.

[5] Fang Mingzhong. Implementation of Open Teaching, to Active Students [J].Survey of Education, 2012(1):98-100.

[6] Ding Wenli. Exploring and Analysing Construction Path of Geography in Junior High School with Efficient Class [J].New Curriculum Research,2014:132.

[7] Liu Bin. Characteristics of Atlas of Middle School Geography (People's Education Press) After Revised [J].Teaching Reference of Middle School Geography,2015(11):42-44.

[8] Li Huacheng. Learning Geography to Get Students Moving [J].Modern Education, 2011(5):49.

[9] Yu Peiying .Into the New Curriculum to Enable Students to "Move Up" [J].Journal of Heilongjiang College of Education, 2015(1):159-160.

[10] Li Wen. Five Breakthrough and Teaching Thinking of Standards Revision about Compulsory Education Curriculum [J].Geography Teaching, 2012(13):9-11.

[11]Zhou Minqin. Explore Life-Oriented Teaching of Geography [J].Journal of Schooling Studies, 2015(23):66. 